\title{
Milchfettgehalt von Sahneeis
}

\author{
Amal Wicke
}

(C) Bundesamt für Verbraucherschutz und Lebensmittelsicherheit (BVL) 2011

In Bezug auf TOP 14 der 94. ALS-Sitzung in Dresden mit folgendem Ergebnis (siehe Protokoll der 94. ALSSitzung vom 08.-09.10.2009):

„Eiscreme mit einem zusätzlichen Hinweis auf die Verwendung von Sahne wie z. B. „Eiscreme mit Sahne“ muss keinen höheren Milchfettgehalt als Eiscreme aufweisen.

Der Arbeitskreis bittet den ALTS um Zustimmung zu dieser Auffassung.“

\section{Beschlussvorschlag der AG Milch und Milcherzeugnisse:}

Dem Ergebnis des ALS wird zugestimmt. Ergänzend dazu soll darauf hingewiesen werden, dass der
Sahneanteil bei Fertigpackungen in diesem Fall über eine Mengenkennzeichnung nach $\S 8$ LMKV angegeben werden muss.

Ein Erzeugnis mit der Verkehrsbezeichnung „Sahne-Eiscreme“ kann allerdings mit der Speiseeissorte Sahneeis verwechselt werden und so zur Irreführung des Verbrauchers geeignet sein.

\section{Beschluss}

Dem Ergebnis des ALS wird zugestimmt. Es wird darauf hingewiesen, dass bei Fertigpackungen der Sahne-Anteil gemäß $\S 8$ LMKV angegeben werden muss. 